\title{
PRODUCTION SYSTEM IN A COLLABORATIVE SUPPLY CHAIN CONSIDERING DETERIORATION
}

\author{
Jaime Acevedo-Chedid; Katherinne Salas-Navarro; Holman Ospina- \\ Mateus; Alina Villalobo; Shib Sankar Sana
}

\begin{abstract}
This research presents a mathematical model for a collaborative planning of the supply chain involving four echelons (supplier, production plants, distribution, retails, or clients). The model seeks to maximize profit (utility) when all members of the chain share information related to demand. It is developed for the aggregate consolidation of different raw materials in cement production. The novelty of the model is the consideration of products that deteriorate in the process and thus it has effect on the production times in the plant and lead time. In this supply chain, quality and compliant products and the return of deteriorated products are two flows. The considerations are lead time, inventories with shortages and excesses, production times in normal and extra days, and subcontracting, among others. A mixed integer linear programming with demand scenario analysis is used to optimize and analyze the uncertainty that is consistent with the performance of the construction sector. The model is formed considering two suppliers, two production plants, two distributors, two retailers and two end customers. Four manufacturing inputs (raw materials) are considered for the manufacture of two types of products. A case study of the cement production supply chain of Cartagena (Colombia) is illustrated. The shared benefit is generated around 5 billion pesos (COP) for all members of the chain in a period of 6 months.
\end{abstract}

\section{Keywords}

Collaborative supply chain; Deteriorating products; Reverse flow 